\title{
"Everywhere you go always take the weather with you": Phenomenology and the pedagogy of climate change education
}

\author{
Patrick Howard, Cape Breton University, Sydney, Nova Scotia, Canada \\ Email:patrick_howard@cbu.ca
}

When, on a summer evening, the melodious sky growls like a tawny lion, and everyone is complaining of the storm, it is the Méséglise way that makes me stand alone in ecstasy, inhaling, through the noise of the falling rain, the lingering scent of invisible lilacs.

- Marcel Proust, 1983

I've looked at clouds from both sides now

From up and down, and still somehow

It's cloud illusions I recall

I really don't know clouds at all - Joni Mitchell, 1968

\section{Abstract}

In no other time in human history has the relationship between human beings, and the biosphere on which we depend, been fraught with such a sense of urgency. Responding to the imminent threat of climate change has focussed our attention on education. There has been a proliferation of international, national and regional programs designed to change attitudes, behaviours, and beliefs associated with the causes of climate change. This paper will look to phenomenology and pedagogy to attempt describe the experience of climate and to help us consider how we may allow the young to live in a time of inevitable climate disruption while nurturing what seems to come to them naturally, an embodied integration into the wonder and awe of the places they live. Also, this paper explores two dominant approaches to climate change education and asks how these approaches articulate an understanding of the essential relationship between humans and the larger living world as reflected through changing climatic conditions.

\section{Introduction}

In these times it is difficult to avoid discussions of climate change and the attendant public discourses of fear. The language describing the effects of climate change and global warming is infused with dire predictions of 'catastrophe', 'danger', 'collapse' and 'extinction.' Human beings have always had a complex relationship with climate and this relationship has had profound impact on human culture and history (Hulme, 2008). But perhaps, as in no other time in the human story, has the relationship between human beings, and the biosphere on which we 
depend, been fraught with such a sense of urgency on a global scale. Those most vulnerable to destructive climatic change endure great physical hardship through complex interplays of culture, history and geomorphology (Protevi, 2009) just as those whose lives are dedicated to mitigating the predicated ecological catastrophe suffer emotionally and spiritually in the face of an overwhelming magnitude of the problems (Thomashow, 1996).

Atmospheric chemist Paul Crutzen coined the term, the Anthropocene, to describe the current era he believes commenced in the $18^{\text {th }}$ century when humans began to influence geologic forces on a planetary scale (Crutzen \& Stoermer, 2000). Michel Serres (1995) echoes a similar observation by noting our current era is a time in which, "global history enters nature; global nature enters history" (p. 4). Serres' notion of history is undoubtedly anthropocentric and belies a tacit assumption based on what Meillassoux (2009) calls correlationalism: the insistence that only humans (or consciousness, which is equivalent for most) bestow meaning and value on reality. Meillassoux's post-Kantian critique seeks to overturn the deeply entrenched philosophical traditions that privilege the human over other entities thereby working to de-center the human. At the same time, American literary scholar Timothy Morton defines the Anthropocene as the "period in which human history intersects decisively with geological time" (2012, p. 7). When humans began to deposit carbon in the earth's crust and into the atmosphere on an Industrial scale, was the precise moment when philosophies were produced which made 'man the measure of all things' and silenced the possibility of talking about non human reality that could be, in any meaningful way, affected by human action (Morton, 2012).

Our Western psyches are seemingly indelibly stamped with the powerful mythos of modernity that launched the Anthropocene. We are steeped in the language and thinking of separateness and dualism. We still perceive, think, and talk in terms of economy versus ecology, people versus environment, culture versus nature, them versus us; and yet, slowly, we are being shown in ever dramatic fashion that we are inextricable participants in earth's systems and flows, constantly affecting and being affected by the dynamic, recursive feedbacks between everything human and natural - that, in essence, the two are one in the same. In responding to the imminent threat of climate change our attention, predictably, is focussed on education. There has been a proliferation of international, national and regional programs designed to change attitudes, behaviours, and beliefs associated with the causes of climate change. This paper will look to phenomenology and pedagogy in an attempt to describe the experience of climate and to help us to begin to think about how we may allow the young to live in a time of inevitable climate disruption while nurturing what seems to come to them naturally, an embodied integration into the wonder and awe of the places they live. Secondly, a preliminary exploration of the dominant approaches to climate change education will be undertaken to determine how these approaches articulate an understanding of the essential relationship between humans and the larger living world as reflected through changing climatic conditions. What is to be a pedagogical response to climate change? What should it mean to educate about climate change? How might a pedagogical response to climate change recover a sense of education that educes and engages, while encouraging spontaneity, insight and reflection? How can we nurture in our children an attunement to the more than human (Abram, 1996), the patterns of weather related to climate, and our deep enmeshment in atmospheres of affect? 


\section{Climate as medium or - What's it like out-side?}

Climate has always carried complex and ambiguous meanings for humans. Human evolution has been shaped through the vicissitudes of our relation with climate. Climatic forces have shaped cultural memory and myth from the Biblical floods of Judaism, Christianity and Islam to the climatic pulsing in seven year cycles that still today gives life to millions of Egyptians living along the Nile. Hulme (2008) points to the earliest attempts at climatic classification by Herodotus and Ptolemy as revealing the precariousness of our relationship with climate. While the Greeks inhabited the forgiving temperate zone of the eastern Mediterranean, the frigid and the torrid klima were regions of danger and death.

The human experience of climate is deeply related to cultural practices and imagination. Climate is bound up in notions of personal and national identity (Golinski, 2007). The human experience of climate can release powerful emotions that may be benign, positive or negative as seen with the advent of Seasonal Affective Disorder (SAD) and its inclusion in the DSM IV as a Major Depressive Event. The condition is defined as a seasonal pattern of depression caused by inordinate sensitivity to seasonal changes (in light or in temperature, for example.) The pathology of "inordinate sensitivity" notwithstanding, the simultaneous ecological and affective concept of SAD provides an interesting entry point to begin to phenomenologically explore the capacity to understand the Anthropocene as an era of increasingly intense interrelation of human affect with the larger living world. What does it mean to be "sensitive" to seasonal and climatic conditions? How are we to more fully describe our physical sensation of climate, and what are we even sensing as being climate? As epistemologist Gregory Bateson asserted, within and around the ecology of 'living forms' an ecology of ideas, or of mind, exists which strictly interacts with the former one. Understood this way, mind is not one and the same with the human self, nor brain; rather, it is an ecological function that reflects the physical, inescapable, interconnection between the self and the environment. David Abram (2010) describes it this way,

Awareness, or mind, is in this sense very much like a medium in which we are situated, and from which we are simply unable to extricate ourselves without ceasing to exist. Everything we know or sense of ourselves is conditioned by this atmosphere. We are intimately acquainted with its character, ceaselessly transformed by its influence upon us and within us. And yet we're unable to characterize this medium from the outside. We are composed of this curious element, permeated by it, and hence can take no distance from it... It remains an enigma, a wonder, not by virtue of any miraculous quality, but by the plain obvious fact that we are in it, and of it. (p. 125-126)

Being that mind is a medium, a middle place where the inside and the outside meet, then we must acknowledge that our experience of our places, our environments is nothing merely subjective, and how we know our places and imagine them is not an abstract activity. Each place in its unique topography, ecosystems, patterns of energy and flow, and cultures represents a specific awareness, or state of mind. What happens if a society becomes fractured and alienated from the precise fusion of elements that is its natural referent? Iovino (2012) posits that in the perspective of the ecology of mind, a cultural and perceptual separation between self and nature is "a form of schizophrenia and, more generally considered, can be seen as the very root of the ecological crisis” (p. 105). How might this expanded notion of mind help us to better understand the experience of climate change? 


\section{Howard}

Climate is defined as, "the long-term manifestations of weather and other atmospheric conditions in a given area or country, now usually represented by the statistical summary of its weather conditions during a period long enough to ensure that representative values are obtained (generally 30 years)" (Oxford English Dictionary, 2001). The concept of 'climate' is inherently abstract, and a scientific determination. The weather conditions being statistically summarized are meteorological parameters such as temperature, rain fall, barometrical pressure, wind force, hours of sunshine, cloud cover etc. It is only as embodied, corporeal beings can we be affected by the 'elemental' qualities of climate. Climate, in this sense, is the perception of a configuration of atmospheric vibrancies as experienced by a sensitive being. In the Anthropocene it may be argued that the sensitivity goes both ways, that the "sensate reciprocity" David Abram (1996) describes as being at the center of our affective intertwining with the environment, can be seen in the state of our environment and its sensitivity to human pressures manifested in 'disordered' climatic patterns and conditions. And yet, is it even possible to experience climate as it is so abstractly defined? How do we experience climate over extended periods of time and differentiate changes in climate over long time frames? To better understand these questions it is important to differentiate the notion of climate from the related concept of weather.

\section{Weather - Lived Time, Lived Body, Lived Place}

From a phenomenological perspective, climate is always sensed as weather, as we do not, in any real sense, perceive averages of meteorological conditions over long periods of time. Weather is defined as, "The short term state of the atmosphere at a specific time and place, including the temperature, humidity, cloud cover, precipitation, wind, etc. (Oxford English Dictionary, 2002). Knebusch (2008) shows the origin of the English weather is the old Germanic weora and refers to a temporary state of the atmosphere. French, on the other hand does not have an equivalent of the word weather. However, temps refers to diachronic time as well as meteorological time, emphasizing the transitory nature of weather. In German, the word wetter has fostered a series of words to capture the relational and the reciprocal. The adjective wetterfuhlig expresses a sensitivity to weather conditions and the verb wittern refers to a sense or sensing of the prevalent atmosphere. The word also exists in the reflexive form sich wittern to capture the perception of "something revealing itself atmospherically, in the same way as when we say in English that "something is in the air" (Knebush, 2008, p. 5).

For people, climate is most commonly associated with seasonal changes as they occur in specific geographical places with which the person has a familiarity and experience of through memory over periods of time. Weather is transitory, elusive, shifting, and variable over short periods of time. However, it is weather that, over longer periods, establishes patterns that may be seen as consistent and stable. The climate over a longer term takes on an implicit regularity; it may be described as typical and adheres to expectations over time, through seasonal shifts and changes. There is a sense of orderliness as seasons and cycles structure time.

Living on the north Atlantic coast of Canada, I am aware of the large scale seasonal patterns in weather and would be able to generally describe the climate of my unique bioregion to a visitor unfamiliar with this place. I am not sure if I could clearly demark on a map, as a geographer could, where the particular bioregion in which I live begins and ends; yet I believe I would sense a shift of numerous obvious and subtle constituents that would tell me I was in 
another bioregion that was not my own. But geographical categorizing is not the point. I know, through my direct lived experience, that I reside on the coast of the North Atlantic. The exact geographical demarcation is not that important. But I imagine people who live on the other coasts of Newfoundland and Labrador, on the green hills of Prince Edward Island, along the spruce-lined shores of Nova Scotia and New Brunswick all the way down Maine's rocky coastline to Cape Ann, and Buzzard's Bay to Rhode Island know it too. They may not know to which of the three geographically distinct zones they belong, as determined by ocean current and water temperature, but they may sense, in a very different way, an embeddedness, a tacit, implicit awareness that their lives are part of a vast web of perceptions and sensations, of a tidal inherency that makes up a living, breathing landscape or, in many ways, a mindscape.

Where I live in Atlantic Canada, the seasons mark the annual cycle with the longest day of the year falling on June $21^{\text {st }}$. The day marks the "official" beginning of summer, yet how we experience the seasonal shifts is a complex interplay of sensate time, body and place. It is late August and I am sitting outside, the days are some of the warmest of the summer. After June $21^{\text {st }}$, the amount of heat available declines as the days grow shorter and the sunlight enters the atmosphere at a lower angle. On a daily basis this is imperceptible to me. The heat continues to build over the summer months until there comes a point when the inflow of solar energy diminishes to balance the outflow of heat. That marks the hottest days - generally late August and early September. And yet, as I sit in the warm breeze I unmistakeably sense Autumn. Subtle signs and changes cumulatively speak and push in on the consciousness that has nothing to do with the time as measured on the calendar. The air cools quickly in the evening and my perception of days growing shorter arises as a full realization. The distinction between 'short days' and 'days growing shorter' is significant and speaks to our understanding of how time and invisible energy flow shape our experience of the seasons. The days of January are short days, though they are growing longer each day. The days of July are long days, though growing shorter each day. Time seems to move in opposite directions at once. We live in a time lag of longer growing shorter, and shorter growing longer, but cannot locate ourselves there. We live in the balance of meteorological time, in the stability of knowing this experience is expected based on previous experiences and memories of past seasons. As climate is concerned, seasons are perhaps the limit of my capacity to perceive on a geological scale. Knebusch (2008) writes, "Seasons refer to the human scale of climates" (p. 6). In relation to longer seasonal cycles and environmental change, I am firmly affixed in the 'natural attitude', pre reflectively immersed in my environment, the atmosphere. It is that through which I move and that which moves through me. The changes that occur around me are subtle, overlooked and often ignored. I go about my everyday life confident and comfortable in the taken-for-grantedness of my lifeworld.

And I know there are shifts in seasonal conditions that blur the distinctions and fall outside our understanding and expectation as indicated by chronological time. In April large moisture laden north easterly winds drop large amounts of snow in the middle of spring, yet there is no mistaking the quality of the snow, the wind, the ambient temperature, the length of daylight all infuse the weather event with an 'in between quality' of neither winter nor spring, but with a tonality that belongs uniquely to itself. We may not have a word to describe the event, but we distinguish readily between these seasons and sub-seasons. Most people are familiar with the term "Indian summer", a stretch of warm, pleasant weather that occurs in the fall. It is not a season in and of itself, yet it belongs to fall, while standing quite separate from it. Indian summer cannot occur in any season other than fall. It is owned by fall, and fall does not cease during a prolonged Indian summer. While our language may be impoverished in describing or naming 


\section{Howard}

these secondary seasons and phases of weather, we are able, through awareness and observation, to note the temporal changes of rhythm and pattern, to recall past events and anticipate them in the future.

It is in this world that I am both observer and participant, but perhaps, in this case, it is more apt to say that observation, in a certain sense, is participation. Haig-Brown writes, “... no man is solely an observer of the natural world... We are basically all hunters, or gatherers, or gleaners or predators, we all feel the weather in our face at times, and the things that stir and change about us stir within us also" (in Grady, 1999, p. 201). As embodied beings we are sensate, designed to perceive our environment. My ears, eyes, skin, nostrils and tongue are receptors, tuned for relationship. The rustling flap, the flitting shadow, the minute shifts in light and sound seem to find their way in and down, to forgotten, or at least neglected spaces within us. Climate as marked by seasonal shift, cycles and energy flows in many respects may be described as a feeling based on a gestalt - a plurality of autumns that become a representation of experiences of patterns, cycles and energies of meteorological conditions and signs that stir within us lifting out affective memories that resonate within us. The subtle tonalities of our life stories are played out and overlaid with seasonal change and atmospheres. I have an "autumn sense" - a composite of autumns past, the wind, the falling leaves and changing colours, bound up with the return to school, the smell of new book bags and children's birthday parties. In Gendlin's (1992) discussion of Heidegger's notion of befindlichkeit - the mood-wise situatedness of being - Gendlin describes the implicitness of feeling, the sense of inherency of feeling, "that is never quite equal to any cognitive units" (p. 52). Gendlin says such feeling is "lifted out”. I know this sense; this is a solicitation to feeling, for there are moments when our lives and the life of the world seem deeply interconnected. On the coast where I live, thick, cold fog is drawn into the bay, skeins of salty vapour envelop the house and descend upon my awareness, dampening my enthusiasm and instilling lethargy deep within my bones it seems. It is these times that I sense the ability to affect and be affected by a world as a living, dynamic landscape capable of its own moods and moments. I sense my perceptions are part of a vast web of perceptions and sensations experienced by other bodies, not just mine and not necessarily human. It is as Merleau-Ponty says, that at the heart of human experience, no matter how abstract or seemingly cerebral, is the body as a plane of exchange. It draws life from the air, sunshine and water; its boundaries are porous, permeable. As it draws from the world, so it contributes. The body allows my entering into relations with all things.

\section{Thing-power as material vitality}

It is only when the ordinary fluctuates, when ruptures, imbalances occur that the implicit character of climate, its regular pattern and cycles and flows become visible. In much the same way health is experienced most acutely in the absence of pain or dis-ease. Such dis-ordered climatic changes invite us to confront the 'strange' or the uncanny. Rising sea levels, more destructive storms, coastal erosion, the disappearance of familiar species and the arrival of unfamiliar ones cause unease, dis-ease even, an eco-sickness and speak to a weirdness and the uncanny in Heidegger's usage of the word as being "not at home”, alienated and distanced from one self. The ability to affect and be affected belongs to people and the environment and both sides might be considered not only co-constituting, but disordered in the current state of affairs. But how am I to understand the experience of being "affected" by weather, climate and the larger living landscape? 
The anxiety associated with the uncanny and the weird may point to an aesthetic dimension to the experience of climate change. Our environmental consciousness is particularly susceptible to sensory and aesthetically mediated impressions. The founding text for the modern environmental movement is Rachel Carson's Silent Spring that encapsulated the complexities of high levels of DDT in the ecosystem as an ecological-aesthetic problem, namely, springtime without birdsong. It made a strong, lasting impression and resonated deeply with people. Alphonso Lingis (2000) writes,

To live is to echo the vibrancy of things. To be for material things, is to resonate. There is sound in things like there is warmth and cold in things, and things resonate like they irradiate their warmth and cold. (p. 108)

This “vibrancy of things" of which Lingis speaks may be described as a vitality. It is the capacity of things - water, storms, land, flora, fauna, and the elementals in all their permutations to impede or block the will and designs of humans and to act as agents with forces, intentionalities, propensities or tendencies of their own, something Bennett (2010) describes as thing-power (p.2). According to Bennett, the idea of thing power is similar to Spinoza's conatus, the active impulsion or tendency to persist. Thoreau described the same force as the Wild, the uncanny presence and irreducibly strange dimension of matter, "an out-side" or as Bennett explains in the context of political theology an "absolute”. While an "absolute” carries with it the connotation of omnipotence and a divine God-head, the word's etymology reveals that which refuses to be known by humans. Absolute as understood through its etymology and Latin origins means to unfetter or to loosen. In that sense the absolute is some-thing that is not an object of knowledge, it is that which we cannot know. And yet, this unknowability is still tied to the limits of human intelligibility. Humans as knowing bodies overlook things, or entities and what they can do. Bennett's notion of thing power attempts to describe the "thing” as actant, and in doing so she tries to "give voice to a vitality intrinsic to materiality, in the process absolving matter from its long history of attachment to automatism or mechanism” (2010, p. 3).

Bennett's attempt to explicate a vital materialism is a response to cultural, linguistic or historical constructivism, which interprets any expression of vital materialism as an effect of culture and the play of human powers. But a tendency toward vital materialism urges the cultivation of a careful attentiveness to what is out-side. In what way may we be open to a world of non-human vitality? How can we both receive and participate in what is given and what is received? How are we to understand what is perceptible arrives through humans but not entirely because of them? What happens when we linger in those moments when we are entranced by objects, atmospheric phenomena, plants, insects, rocks, artifacts and take them as clues to the material vitality we share with them? Some would argue this requires a naiveté, an animistic, primordial, or worse, primitive understanding that we dispensed with long ago. And yet, my own experience, tells me that far from being primitive, animism and people who possess a sense of vital materialism have a reality which holds many important insights for our relationship with each other and the Earth. Stephan Harding (2006) writes, "animistic perception is archetypal, ancient and primordial: that the human organism is inherently predisposed to seeing nature as alive and full of soul, and that we repress this fundamental mode of perception at the expense of our own health , and that of the natural world" (p. 21). While considered backward and unsophisticated by Western scholars for lacking objective validity I can turn to my own experience and the experience of others to understand the vitality, the conatus, the Wild, the Absolute that surrounds me and of which I am part. 


\section{Howard}

Scientific explanations cannot capture the experiences of this elemental vitality, for science abstracts the sensory experience labelling it merely subjective and therefore, null and void. Strangely, too, projecting divine or super-natural explanations also abstracts the experience, but in a different way. By ascribing the experience to the super-natural, I remove the possibility that there is a commonality, an interdependence, that I, as perceiver, and the thing I perceive, are as part of the same elementals. Relying on either the divine, or the scientific, may be seen as a denial of our embeddedness and our need for attentiveness to the out-side. Sigurd F. Olsen (1982), a physicist, in his essay Northern Lights, expresses the inability of Reason, of a scientific orientation, to give voice, in any meaningful way, to a deeply felt presence of the atmospheric phenomena. Olsen describes beautifully the experience of skating down a seven mile long clear sheet of lake ice in Canada's north. Suddenly, as he is skating, he is aware of the aurora dancing in the heavens above him and at the same time being reflected in the ice below him. "At that moment, I was part of the aurora, part of its light and of the great curtain that trembled above me.” As he lay on the ice to rest he thinks,

I knew what the astronomers and the physicists said, that they are caused by sunspots and areas of gaseous disturbances on the face of the sun that bombarded the earth's stratosphere with hydrogen protons and electrons of oxygen, nitrogen, helium. Here they produced all the colours of the spectrum. It was all very plausible and scientific, but tonight that explanation left me cold. I was in no mood for practicality for I had just come skating down the skyways themselves and seen the aurora from the inside. What did the scientists know of what I had done? How could they explain what had happened to me and the strange sensations I had known? (Olsen, 1982, p. 97)

Olsen struggles to make sense of his experience. We can imagine him laying there fully open to a living, breathing world. His body is supported by the solidity of ice beneath him, his ears attuned to the cracking, shifting forces, his eyes scan the spectacle of light, the clear frost stings his nostrils and sends his breath skyward in a hoary spume. At the moment when the experiencing body and its divergent senses meet up in the world, when the living world is present in all its depth is when Olsen, the scientist, rejects, science. He looks elsewhere to make sense of his experience;

Much better the poem of Robert Service telling of great beds of radium emanating shafts of light into the darkness... How infinitely more satisfying to understand and feel the great painting of Franz Johnson of a lone figure crossing a muskeg with the northern lights blazing above it. I stood before that painting in the Toronto Art gallery one day and caught all the stark loneliness, all the beauty of the cold of that scene and for a moment forgot the busy city outside... I knew nothing then of protons or atoms and saw the northern lights as they should be seen. (p. 97)

It seems for Olsen seeing the aurora as they should be seen becomes an aesthetic experience wherein what is phenomenally given, that is, sensed, exerts an external effect in accordance with its vitality to fill up the space that surrounds one with tensions, and a presence articulated through qualities undeniably sensed in the bodily presence of human beings. 


\section{Aesthetics and the co - creation of atmosphere}

Gernot Böhme (1992; 1993; 2003) can help us better understand Olsen’s experiences in the art gallery and while he lay on the frozen lake. Böhme posits a new aesthetics, as "a theory of perception in the full sense of the term, in which perception is understood as the experience of the presence of persons, objects and environments” (1993, p. 116). Böhme's theory is based on ecological embodiment and on a phenomenological, materialist aesthetic theory of nature. Böhme posits that beauty, like other aesthetic experiences, is an experience of co-presence, of the shared reality of subject and object. He puts forward a new aesthetics to be understood as the production of atmospheres. Böhme writes, "As regards reception it is a theory of perception in the full sense of the term, in which perception is understood as the experience of the presence of persons, objects and environments” (1993, p. 116).

Böhme describes in another way what may be understood as Lingis’ notion of vibrancy and vitality. Vibrant matter depends on the medium through which it is perceived. A thing's eidos unfolds into the medium of its presence, "the ways in which it goes forth from itself" (Böhme, 1993, p. 121) and thereby affects this medium. Böhme writes of the "ecstatics of nature" to explain the interplay of self-revealing and self-concealment at work in perception. Böhme is concerned with the "and" - the in-between in the relation of environment and human. This in-between space, for Böhme, is atmosphere. Atmospheres for Böhme are spaces in that they are "tinctured" through "the presence of things, of persons or environmental constellations, that is through their ecstasies” (1993, p. 121). Böhme challenges classical ontology which sees the form of a thing as something limiting or enclosing. The form of a thing, says Böhme, also exerts an external effect. "It radiates as it were into the environment... and fills it with tensions and suggestions of movement," (p. 121) creating spheres of the presence of something. Böhme writes,

Conceived in this fashion, atmospheres are neither something objective, that is qualities possessed by things, and yet they are something thinglike, belonging to the thing in that things articulate their presence through qualities - conceived as ecstasies. Nor are atmospheres something subjective, for example determinations of a psychic state. And yet they are subjectlike, belong to the subject in that they are sensed in bodily presence by human beings and this sensing is at the same time a bodily state of being of subjects in space. (p. 122)

This gives new meaning to Proust's words in the epigram of this paper, to stand " alone in ecstasy, inhaling, through the noise of the falling rain, the lingering scent of invisible lilacs.” The vital presence in which the speaker is immersed is described by Böhme as ecstasies. In this way, Böhme's new aesthetics can help us think about, in interesting ways, how we experience weather, the daily biospheric changes unfolding in our local bioregions and perhaps attune our awareness to larger, more imperceptible shifts in larger climatic patterns and how this bears on our emotions, thoughts and actions. Changes in weather influence our physical and emotional beings.

The title of this paper, "Everywhere you go always take the weather with you" is a line from a pop song by the Australian group Crowded House. I am not sure of the original intent, or meaning of the line, but for me it somehow speaks to the steadiness and ubiquity of our focus on the weather and climate. Talk of the weather is the social currency between neighbours, friends, and strangers. Where I live, very few conversations do not begin and end without reference to 


\section{Howard}

the current or projected weather conditions. We draw on a strong temporal awareness when we talk of weather and climate. We talk of the recent weather, and the weather to come; we remember the conditions from last month and predict future seasons. We discuss the weather far in the past. Each of these temporal frames form a key aspect of human experience of weather. There is safety in weather talk and an immediate connection with an-other is acknowledged. My next door neighbour will invariably initiate all of our conversations with an observation of the current conditions, "Chilly today isn't it?" or a comment on the projected weather "We are going to get a drop of rain I believe?" Two key themes, time and talk, guide our everyday relationship with weather and climate. Our perception of weather is characterized first by the immediacy of the present. What the weather is like at this time, right now, on this day. We are able to move from the immediate to a sense of the changing conditions over years or seasons. And it is in this sense we are likely to make observations about climatic conditions marked by an attentiveness to the changing cycle of the seasons. "This is the most rain we've had in years." and "I took off my winter tires two weeks earlier this year than last" demonstrates a perception of temporal units defined by annual or seasonal shifts and comparisons made through remembered experience. Thirdly, our weather talk is marked by a sense of generational shifts and aligns most closely with what could be understood as climate change, the passing through cycles that may be decades or even centuries in length. In many places around the world people will note that the weather was different in their parents' and grandparents' time and will make reference to stories passed down through generations to verify their observation (Harley, 2003).

The weather is rarely out of our attention, with the media, apps for our mobile devices and 24 hour weather channels devoted to keeping us fully informed about the meteorological conditions. And yet, despite our best efforts and all the affordances of modern forecasting technology, the weather and its ability to perplex and surprise through a constantly shifting flux of energy and flow, remains an enigma. But suppose we were to turn around our interest in the changing atmospheric conditions to understand its affective dimension from within us as breathing, feeling, sensate beings immersed in and permeated by the elemental flux? As embodied beings we are fine tuned for relationship, we all experience the variations in atmospheric conditions and have evolved to perceive a range of atmospheric conditions. We take in and project the changes in the ambient conditions and as the dispositions in the weather shift, so too do our dispositions or moods. How we are, our being is affected as the tensions, and tones of the atmosphere move us perceptibly and imperceptibly. Brilliant sunshine, rain, fog, drizzle, humidity, low cloud all seem to inhabit our bodily experience at different times and speak to our essential entwinement in a larger living field.

This leads us to what will be an appropriate pedagogical response to the imminent threat of climate change. How might we think about a climate change education that honours the embodied integration, wonder and awe that seems to come naturally to the young. In what way is climate disruption a deeply relational element of how children experience seasonal change. Writer and scientist Sandra Steingraber (2013) describes in her essay, The Discontent of our Winter: Are Reliable Seasons Gone for Good?, the recent unpredictable weather patterns in New York state and how she and her children are deeply affected by it. She writes,

Let the record show that in February 2013 in Trumansburg, New York the children gave up on winter. As a season it was no longer reliable. You could wake up in the morning to a wonderland — snowflakes dutifully falling, the front yard all white, perfect, hushed, 
squeaky — and by the time school let out in the afternoon, the miraculous world had already reverted back to brown, gray, mushy, yucky.

“Don’t get excited,” said Faith to Elijah right before Valentine’s Day when he looked out the window at first light and announced a fresh snowfall. "It won’t last.” (p. 1)

Steingraber predicts that her children and all those children who are between ten and fifteen years old will have a fundamentally different "worldview" than children born even a few years before them. "My kids will, in fact, be the last human beings to remember a stable, predictable procession of seasons" (Steingraber, 2013, p. 1). The writer laments the loss of deep cultural connections and lived experiences indelibly associated with childhood winter play. The age old skills of snow fort construction, sledding, snow ball making, the sights, sounds, smells of winter precipitation in all its icy, slushy, fluffy manifestations are disappearing in only a few short years, along with knowledge of "the methods of tucking snow pants into boots... the opinions on gloves versus mittens, and the proper way to make a snow angel” (p. 1). What does it mean for childhood, for identity formation, for the creation of cultural knowledge and the deep experience of place when such time honoured rituals, and activities are disrupted and in danger of disappearing? What are those children sensing or experiencing when the implicit character of climate, the regularity and orderliness over time is disrupted? What may be considered an appropriate pedagogical response?

\section{Pedagogical Imperative and Climate Change Education}

\section{Climate science and coming to know}

The attempts to address the problem of climate change through education are varied and proliferating. By looking at two very different climate change education programs, namely, NASA Innovations in Climate Education (NICE) and Journey North we can better understand how educational approaches reveal an orientation to the world that either fosters a sense of interconnection and our integration into a dynamic whole through participation and the enhancement of our perception, or how the program reflects an understanding of the natural world as a collection of mechanistic parts and processes that can be understood and controlled through quantification and systematic experimentation. The National Aeronautics and Space Administration (NASA) has created a climate change education program that is firmly oriented in the latter worldview. The program NASA Innovations in Climate Education (NICE) is described as;

.... a portfolio of 71 climate education initiatives that span across the nation and contribute to the development of a climate-literate public and a climate-related STEM workforce... all projects share a common element - they all make use of NASA Earth observation data and/or Earth system models in their education work. From elementary students in Alaska to college freshman in Florida... the NICE project is developing a community of practice among climate science educators. This community of educators, working together, expects to significantly contribute to increasing the climate literacy of the United States public. (NASA, 2013) 


\section{Howard}

The NASA program description uses interchangeably the terms, climate education and climate literacy while climate education is folded into climate science education. A key program document defines climate literacy,

...climate science literate individuals understand how climate observations and records as well as computer modeling contribute to scientific knowledge about climate. They are aware of the fundamental relationship between climate and human life and the many ways in which climate has always played a role in human health. They have the ability to to make informed and responsible decisions with regard to actions that may affect climate... (US Global Change Research Program, 2009, p. 4)

Thousands of students are learning about the natural environment and appropriate humanenvironment relationships as a subset of the science curriculum. The NASA program is environmental education that emphasizes technology, trade and resources and acknowledges that climate literacy allows students to take advantage of the “opportunities" (2009, p. 4) made possible by climate change. The underlying belief of curriculum developers is that climate science will inculcate in children a knowledge that results in an appreciation and a valuing of the larger life forces on which we depend and hence a sensitive, respectful, and restrained use of nature. Without a doubt, science has its place in climate change education. The abstraction, the impersonal, the objectifying stance of science can help us know some things with a degree of certainty. It has produced an invaluable body of knowledge about intricate meteorological systems, the value of species and the complexity of species diversity. Scientific study provides information on which we base decisions that will directly affect the health and well being of this planet and in turn each of its inhabitants. However, the knowledge about climate change and shifting weather patterns gained in this classroom begs the questions, "In what way do our children know the living Earth and what value do they give it?” Wendell Berry (2000) says, "We know enough of our history by now to be aware that people exploit what they have merely concluded to be of value, but they defend what they love" (p. 39). Does the technical, resourcist bias of the sciences with its dispassionate, objectifying language make it incapable of bearing the burden that we place upon it?

A recent story on the National Public Radio website heralded the introduction of climate change science standards that recommend public school students in the U.S learn about "the climatic shift taking place” (Ludden, 2013, n.p.). To demonstrate the need for climate science education the writer asks, "We all learn the water cycle. But how many can draw a picture of the carbon cycle?” (Ludden, 2013, n.p.). Can we nurture ecological sensitivity by diagramming the carbon cycle and the complexities of the greenhouse effect? Science reduces; reductionism is invaluable to scientists; it is what they do. It is indispensable to all of us. There are times we must know the composition of things, how they hang together, what laws and principles govern their behaviour. However, life is a particularity, a vibrancy, a vitality and a relationality of embeddedness in place that is unavailable to empiricism and objectivism. Knowing living systems calls for a kind of sensitivity, the pathic, the felt - a "living way of knowing" (Jardine, 1998, p.95), that is perhaps not a "knowing" at all -at least not in the sense of knowing as we usually consider it. Things cannot survive as abstractions, as categories on charts and diagrams, but only as unique, individual entities imbued with a vitality that perhaps we cannot know. .

The instrumental rationalism and the technocratic, managerialist language that is dominant in education today is pervasive and powerful. The discourse reflects a way we have come to know the world - an epistemology. But what happens when epistemology becomes 
ontology? In other words, what are the implications when the discourse of science-technologyindustry claims to reflect the physical reality of the natural world and constructs how humans are to "be" in the world? What happens when the language of science-technology-industry, so prevalent in our classrooms consigning the Earth to mere concept and life to mere resources, is largely responsible for strongly held cultural beliefs about the way the world "really is" ? Do our children see the living world as a machine? Does the metaphor become identity? Does it lead one to believe that the Earth and all its creatures are mere human artefacts?

E.F. Schumacher said, "The volume of education... continues to increase, yet so do pollution, exhaustion of resources, and the dangers of ecological catastrophe. If still more education is to save us, it would have to be education of a different kind; an education that takes us into the depth of things" (in Sterling, 2001, p. 21). Our society is in need of a highly ecologically literate citizenry as in no time in the past. To achieve this we must move beyond the scientific into a conversation designed to bring to light our strongly held beliefs and values concerning our relationship with the more-than-human-world.

\section{Enmeshment in the particular: The J ourney North}

A second approach to understanding the larger meteorological forces at play in our world is called Journey North: A Global Study of Wildlife Migration and Seasonal Change. The program describes itself this way:

Seasonal change is all around us. We see it in the length of a day, in the appearance of a flower, in the flight of a butterfly. Journey North engages students and citizen scientists around the globe in tracking wildlife migration and seasonal change. Participants share field observations across the northern hemisphere, exploring the interrelated aspects of seasonal change... through interrelated investigations, students discover that sunlight drives all living systems and they learn about the dynamic ecosystem that surrounds and connects them.(Annenberg Learner, 2013)

The language is very different from the NASA program. While still science based, the orientation is toward careful observation and encountering natural phenomenon intimately, attuning oneself to subtle shifts and changes apparent over time. Children are encouraged to develop perceptual powers through practice and perseverance. David Seamon (1998) reminds us that the "proto- phenomenologist" Goethe argued for training our perceptual powers and by doing so, Goethe maintained that “as a person's abilities to see outwardly improve, so too do his or her inner recognitions and perceptions become more sensitive, 'Each phenomenon in nature, rightly observed, wakens in us a new organ of inner understanding' (1998, p. 3). Seamon goes to say, "As one learns to see more clearly, he or she also learns to see more deeply. One becomes more "at home" with the phenomenon, understanding it with greater empathy, concern and respect” (1998, p. 3). The Journey North program, for example, encourages children across North America to observe closely for the first sighting of a robin, to record the date, to observe their behaviour carefully and listen for the first robin song they hear. This information is entered into the website and data generated allowing children across different zones and regions to share their findings and observations as they learn about the ecology and life cycle of the robin. 


\section{Conclusion}

Ecology can be located in two domains; first, in the emotional and felt significance of our relationships with the more-than-human world, and second, in processes of signification and symbolic representation, that is, in the languages and disciplines that address those relationships. I use the notion of ecology as a way to open human awareness to our fundamental participation in the biotic community - in our bioregion. Ecological understanding is associated with the following commonalities: a focus on relationships, interdependence, and interconnectedness. These relationships are understood explicitly to be nested in a larger web of relations that include both the cognitive and the biological; accordingly, ecological relationships are complex and holistic, implicating the infinite in the particular. Learning to awaken and interpret our bodily felt experience of the claims of the biotic community is at heart a pedagogical and practical task. There is also a moral and ethical imperative present in this project as children are invited to acknowledge the human-nature relationship as a relationship. The demand here is to find ways to talk about the human-nature relationship that does not place humans outside of the natural world, that is, to clarify how it is we relate to the more-than-human while also being an embodied part of a bioregion, involved in its processes.

The leading of children into a deeper sense of their relatedness to a living whole, to invite children to pay close attention to the sensible and the interplay of the world and the felt-sense within them, is inherently a pedagogical undertaking. The human journey through life is undeniably a relational one. We grow and realize our potential as we move into deeper and wider contact with the world. As we enter into more encompassing realms of otherness we build a sense of commonality and belonging with others. The sense that our relationality should extend beyond the human realm is tacit; there is shared recognition that our humanity is incomplete until we have established our relations with the larger natural world. The child, the classroom, the community are part of a much larger whole and what emerges out of this understanding is a deeper sense that local issues are global issues, that our relationship with the Earth, and issues of climate, health, peace, social and environmental justice are interconnected. Perhaps, even at this point in our human history, it is not so much about "solving the problem" of climate change, or yielding to fear, as it is, through our attunement and awareness, of embracing instability, change, and times of chaotic turbulence and developing our perceptual powers to cultivate a sense of awe, wonder, and reverence for vital entities that lay beyond our control, that are out-side our knowing, and perhaps, un-knowable.

\section{References}

Abram, D. (1996). The spell of the sensuous. New York: Vintage.

Abram, D. (2010). Becoming animal: An earthly cosmology. New York: Pantheon.

Annenberg Learner. (2013). Journey north: A global study of wildlife migration and seasonal change. Retrieved www.learner.org/jnorth

Bennett, J. (2010). Vibrant matter: A political ecology of things. Durham: Duke University Press.

Berry, W. (2000). Life is a miracle: An essay against modern superstition. Washington, DC: Counterpoint. 
Böhme, G. (1992). An aesthetic theory of nature: An interim report. Thesis eleven, 32, 90 -102.

Böhme. G. (1993). Atmosphere as the fundamental concept of a new aesthetics. Thesis eleven. 36, $113-126$.

Böhme, G. (2003). The space of bodily presence and space as a medium of representation. In M. Hardy, A. Losch \& D. Verdicchio (Eds). Transforming spaces: The topological turn in technology studies. Retrieved www.ifs.tudarmstadt.de/gradkoll/publikationen.transforningspaces.html

Crutzen, P. \& Stoermer E. (2000). The anthropocene. Global change newsletter, 41(4), 17 -18.

Gendlin, E. (1992). Befindlicheit: Heidegger and the philosophy of psychology. In K. Hoeller (Ed.). Heidegger and psychology. New York: Brill.

Golinski, J. (2003). Time, talk and weather in eighteenth century Britain. In S. Strauss \& B. Orlove (Eds.) Weather, climate and culture,(pp.17-38). New York: Berg.

Grady, W. ( Ed.). ( 1999). Bright stars, dark trees, clear water. New Hampshire: David R. Godine.

Harley, T. (2003). Nice weather for the time of year: The British obsession with the weather. In S. Strauss \& B. Orlove (Eds.) Weather, climate and culture,(pp.103-119). New York: Berg.

Hulme, M. (2008). The conquering of climate: Discourses of fear and their dissolution. The Geographical Journal, 174 (1), 5 - 16.

Iovino, S. (2012). Restoring the imagination of place: Narrative re-inhabitation and the Po Valley. In T. Lynch, C. Glotfelty \& K. Armbruster (Eds.). The bioregional imagination: Literature, ecology, and place. (pp. 100 -117). Athens, GA: University of Georgia Press.

Jardine, D. (1998). Birding lessons and the teaching of cicadas. Canadian Journal of Environmental Education. 3, 92-99.

Knebusch, J. (2008). Art and climate (change) perception: Outline of a phenomenology of climate. In S. Kagan \& V. Kirchberg (Eds.). Sustainability : A new frontier for the arts and cultures.( pp. 242 -261) Frankfurt: Verlag fur Akademische Schriften.

Lingis, A. (2000). The murmur of the world. In W. Brogan and J. Risser (Eds.), American continental philosophy. Bloomington: Indiana University Press.

Ludden, J. (2013). A hot topic: Climate change coming to classrooms. Retrieved http://www.npr.org/2013/03/27/174141194/a-hot-topic-climate-change-coming-toclassrooms?sc $=\mathrm{emaf}$ 
Meillassoux, Q. (2009). After finitude: An essay on the necessity of contingency. (R. Brassier, Trans.). New York: Continuum.

Morton, T. (2012). The Oedipal logic of ecological awareness. Environmental Humanities, 1,7 12.

National Aeronautics and Space Administration. (2013). NASA innovations in climate change. Retrieved http://gcce.larc.nasa.gov/node/7

Oxford English Dictionary (2002). Oxford: Oxford University Press.

Olson, S. (1997). Singing wilderness. Minneapolis, MN: University of Minnesota Press,

Protevi, J. (2009). Political affect: Connecting the social and the somatic. Minneapolis, MN, University of Minnesota Press.

Seamon, D. (1998). Goethe, nature and phenomenology. In D. Seamon and A. Zajonc (Eds.). Goethe's way of science: A phenomenology of nature, (pp. 1-14). Albany, NY: State University of New York Press.

Serres, M. (1995). The natural contract. ( E. MacArthur \&W. Paulson, Trans.). Ann Arbor: University of Michigan

Steingraber, S. (2013). The discontent of our winter: Are reliable seasons gone for good. Orion. May/June. Retrieved http://www.orionmagazine.org/index.php/articles/article/7487/

Sterling, S. (2001). Sustainable education: Re-visioning learning and change. Bristol, UK: Green Books.

Thomashow, M. (1996). Ecological identity: Becoming a reflective environmentalist. Boston: MIT Press.

US Global change Research Program. (2009). Climate literacy: The essential principles of climate science. Retrieved http://downloads.globalchange.gov/Literacy/climate_literacy_highres_english.pdf 